\title{
Advantages and Pitfalls of Capillary Electrophoresis of Pharmaceutical Compounds and Their Enantiomers in Complex Samples: Comparison of Hydrodynamically Opened and Closed Systems
}

\author{
Marián Masár ${ }^{1}$ D, Jasna Hradski ${ }^{1}$, Martin G. Schmid ${ }^{2}$ and Roman Szucs 1,3,*(D) \\ 1 Department of Analytical Chemistry, Faculty of Natural Sciences, Comenius University in Bratislava, \\ Mlynská Dolina CH2, Ilkovičova 6, SK-84215 Bratislava, Slovakia; marian.masar@uniba.sk (M.M.); \\ hradski1@uniba.sk (J.H.) \\ 2 Department of Pharmaceutical Chemistry, Institute of Pharmaceutical Sciences, University of Graz, \\ Universitätsplatz 1, A-8010 Graz, Austria; martin.schmid@uni-graz.at \\ 3 Pfizer R \& D UK Limited, Ramsgate Road, Sandwich CT13 9NJ, UK \\ * Correspondence: roman.szucs@pfizer.com
}

Received: 4 September 2020; Accepted: 16 September 2020; Published: 18 September 2020

\begin{abstract}
Several research disciplines require fast, reliable and highly automated determination of pharmaceutically active compounds and their enantiomers in complex biological matrices. To address some of the challenges of Capillary Electrophoresis (CE), such as low concentration sensitivity and performance degradation linked to the adsorption and interference of matrix components, $\mathrm{CE}$ in a hydrodynamically closed system was evaluated using the model compounds Pindolol and Propranolol. Some established validation parameters such as repeatability of injection efficiency, resolution and sensitivity were used to assess its performance, and it was found to be broadly identical to that of hydrodynamically opened systems. While some reduction in separation efficiency was observed, this was mainly due to dispersion caused by injection and it had no impact on the ability to resolve enantiomers of model compounds even when spiked into complex biological matrix such as blood serum. An approximately 18- to 23 -fold increase in concentration sensitivity due to the employment of wide bore capillaries was observed. This brings the sensitivity of $\mathrm{CE}$ to a level similar to that of liquid chromatography techniques. In addition to this benefit and unlike in hydrodynamically opened systems, suppression of electroosmotic flow, which is essential for hydrodynamically closed systems practically eliminates the matrix effects that are linked to protein adsorption.
\end{abstract}

Keywords: Capillary electrophoresis; hydrodynamically opened and closed systems; chiral separation; pharmaceutical analysis; serum analysis

\section{Introduction}

The determination of Active Pharmaceutical Ingredients (APIs) in biological fluids such as serum, plasma or urine is essential for several research disciplines such as drug pharmacology, drug metabolism, pharmacokinetics, as well as forensic and clinical toxicology. Routine, high throughput quantitative determinations of these compounds require that applied analytical techniques are sufficiently simple to perform while amenable to automation as well as providing adequate selectivity and sensitivity [1]. Capillary Electrophoresis (CE) is particularly suitable for the analysis of diverse types of APIs covering cationic, anionic as well as neutral analytes as it offers a wide range of separation modes in combination with a wide variety of detection techniques. Short analysis times, high resolution and high separation efficiency, in addition to low reagent costs and minimal sample requirements, make this technique 
particularly attractive [2,3]. Besides the obvious advantages, the analysis of APIs in complex biological samples can often be challenging due to multiple interferences from matrix components. An example of these are proteins, which are often present in these samples at very high concentrations and have a tendency to adsorb onto the inner wall of bare fused silica capillaries. This can lead to unpredictable fluctuations of electroosmotic flow (EOF) and consequently can cause highly variable migration velocities of analytes [4]. Slow rates of association and dissociation processes involved in the interaction of some of the analytes with proteins can significantly impair separation efficiencies due to electrodiffusion [5,6]. Additionally, biological fluids usually contain high concentrations of salts, which can have an adverse effect on the resolution of some analytes due to an increase in the electromigration dispersion of the matrix components. Besides high salt content, biological fluids also represent relatively complex systems with multiple chemical components present. This can lead to either an increased risk of comigrations with the analytes of interest especially when non-selective detection techniques are employed or signal suppression when mass selective detection is used. Due to low therapeutic concentrations of most pharmaceutical drugs their concentration levels in biological fluids are very low (ppb to ppm) [7]. Detection sensitivity of CE is, however, generally considered inferior to other separation techniques such as High-Performance Liquid Chromatography (HPLC). This is due to the restriction on sample injection volume $(\mathrm{nL})$ because of the small internal diameter (i.d.) of the capillary tubes employed as separation compartments.

The vast majority of CE applications is carried out using capillaries with i.d. between 20-75 $\mu \mathrm{m}$. This restriction is imposed due to the hydrodynamic flow dispersion [8], which becomes the prevalent cause of dispersion in capillaries of larger i.d. [9]. Additionally, larger i.d. capillaries are prone to excessive heat generation associated with the passage of electric current through them. This also contributes to zone dispersion, but in extreme cases, it can cause thermal degradation of analytes or breakdown of the current due to buffer boiling [10]. The moderate concentration sensitivity of current $\mathrm{CE}$ detection systems constitutes a significant challenge in achieving the required limits of detection (LOD) or quantitation for contemporary industrial applications. To overcome some of these challenges, extensive sample pre-treatment has become common practice in the analysis of biological fluids. This is carried out with two major objectives: (1) the removal of potentially interfering matrix components (sample clean-up); and (2) an increase of analyte concentration (sample pre- concentration).

An alternative way of increasing sample load-ability is to carry out CE analysis in wide bore $(320 \mu \mathrm{m}$ i.d.) capillary tubes. This wide bore capillary format also provides a longer optical path when compared to the conventionally used 50-75 $\mu \mathrm{m}$ i.d. capillaries thus improving detection sensitivity. To overcome the above-mentioned challenges posed by hydrodynamic dispersion, CE experiments employing wide bore capillaries can be performed in an hydrodynamically closed separation system (CSS). Such a system, originally developed for Capillary Isotachophoresis, but also applied in CE [8,11,12], prevents any hydrodynamically induced movement of the separation medium. In fact, under hydrodynamically closed conditions, any bulk movement of a separation medium must be prevented [11]. Papers dealing with various tools for effective and reproducible suppression of the EOF in CE capillaries can be found elsewhere [4,13-15].

In this contribution, we carried out a feasibility study aimed at investigating the performance of $\mathrm{CE}$ as applied to the analysis of APIs and their enantiomers in serum using 50 and $320 \mu \mathrm{m}$ i.d. capillary tubes. The potential benefits of wide bore tubes were assessed against the expected increase of thermal dispersion due to inherent thermal effects. The electroosmotic dispersion typically associated with operations in a closed environment was eliminated by suppression of EOF through dynamic coating of the capillary walls. The impact of this surface modification on the reduction of the serum protein adsorption on capillary walls, which in turn leads to the improvements of the reproducibility of the electrokinetic velocities of analytes was also studied. 


\section{Results and Discussion}

\subsection{Comparison of Hydrodynamically Opened and Closed Separation Systems}

An hydrodynamically opened separation system (OSS) is the most common experimental setup for performing CE experiments in which reservoirs containing separation medium are exposed to atmospheric pressure. The capillary, which is filled with the separation medium (buffer), is fixed between these reservoirs. In this most basic experimental setup, analytes migrate from one end of the capillary (injection end) to the other end of the capillary (detection end) by a combination of electroosmotic movement and electrophoretic migration. The latter is facilitated by the analyte charge and electric field applied across the capillary. Separation of analyte zones is achieved by differences in their intrinsic electrophoretic mobilities $\left(\mu_{\mathrm{ep}}\right)$.

CE in OSS can be performed either with or without EOF. EOF is a flow of bulk liquid which originates from charge separation between the capillary wall and the separation medium. Its direction depends on the charge of the excess ions in the solution. If the electric field across the capillary is maintained constant by keeping the concentration of analytes low relative to the concentration of the separation buffer, then the EOF does not contribute to the dispersion of separated zones [8,16] due to its plug-like velocity profile. Under these circumstances EOF affects ion mobilities of all analytes equally, as it reduces or increases the magnitude of their electrophoretic velocity. Although EOF has a great influence on resolution in CE, many applications require its elimination in order to prevent electrostatic adsorption of analytes on capillary walls. EOF elimination can be achieved by means of either static chemical modification or dynamic capillary wall modification [4]. The latter approach is more flexible, and requires the addition of EOF suppressors to the separation medium [11,17]. Hydrodynamic flow (HDF) across a capillary, which can be generated by hydrostatic pressure difference between both capillary ends, is generally detrimental to the performance of CE as it adds to the dispersion of separated zones due to its parabolic velocity profile [18]. This flow is eliminated by ensuring that the level of fluid in both reservoirs is equal throughout the separation process and by limiting the i.d. of capillaries typically to $75 \mu \mathrm{m}$.

In hydrodynamically closed separation systems (CSS), the detection end of the capillary is usually separated from the buffer reservoir by a mechanical barrier in the form of a semipermeable membrane $[18,19]$. This means that one end of the capillary is practically blocked for the bulk of the separation medium as only ions can be electrophoretically transported across this membrane. This prevents the build-up of the hydrostatic pressure difference and eliminates HDF [18]. With CSS it is, therefore, possible to use capillaries with a larger i.d. As the zeta-potential of the membrane differs from that of the separation compartment, this gives rise to volume velocity differences and consequently increases the dispersion of separated zones through so called electroosmotic dispersion [18]. It is, therefore, necessary to suppress EOF when performing CE separations in CSS.

To compare OSS and CSS, we carried out CE analysis of two model pharmaceutical compounds, Pindolol (PDL) and Propranolol (PPL). Estimated basic pKa values of these compounds is approximately 9.5, calculated using ACD Percepta software (ACD/Labs, Toronto, ON, Canada), and at the pH of the separation buffer $(\mathrm{pH}=3.7)$ they possess a positive charge. Figure 1 shows the separation of these two compounds under three scenarios: a) in OSS with EOF (OSS-EOF), b) in OSS with suppressed EOF (OSS-sEOF), and c) in CSS with suppressed EOF (CSS). The separation buffer for all systems was identical except for systems with suppressed EOF, where $0.05 \%(w / v)$ methylhydroxyethylcelullose (MHEC) was added. $0.1 \mathrm{mmol} / \mathrm{L}$ of diethylenetriamine (DETA) was also added to the separation buffer to prevent compound adsorption on the walls of separation compartments [20].

In our attempt to compare the three systems, we focused on four criteria: repeatability of migration times, separation efficiency, resolution and sensitivity. To eliminate the impact of instrument set-up as much as possible we selected detectors with nearly identical setting for both OSS and CSS experiments. Table 1 lists some of the data for these three systems expressed as the average of ten repeated injections of the model sample. 
(a) $1 \mathrm{mAU} \perp$

(b)

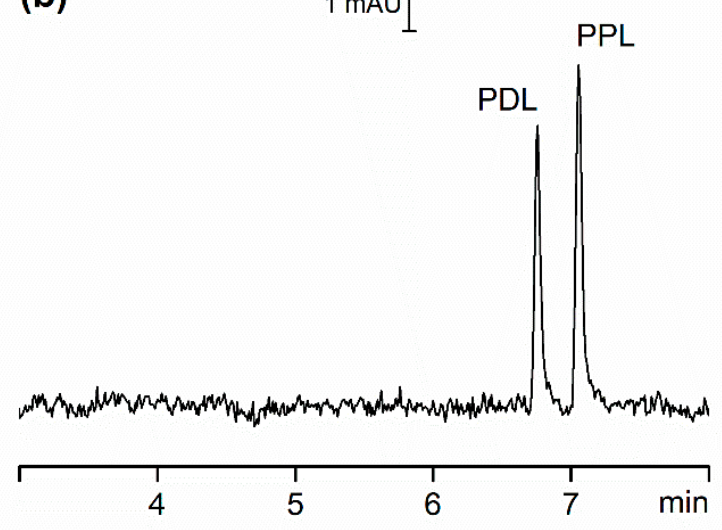

(c)
$2 \mathrm{mAU}$

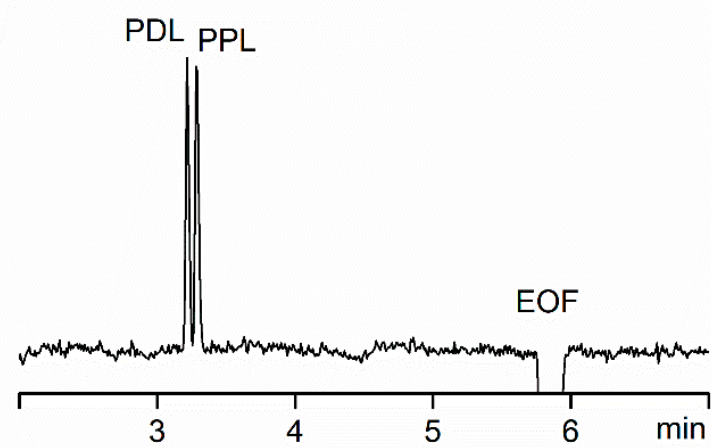

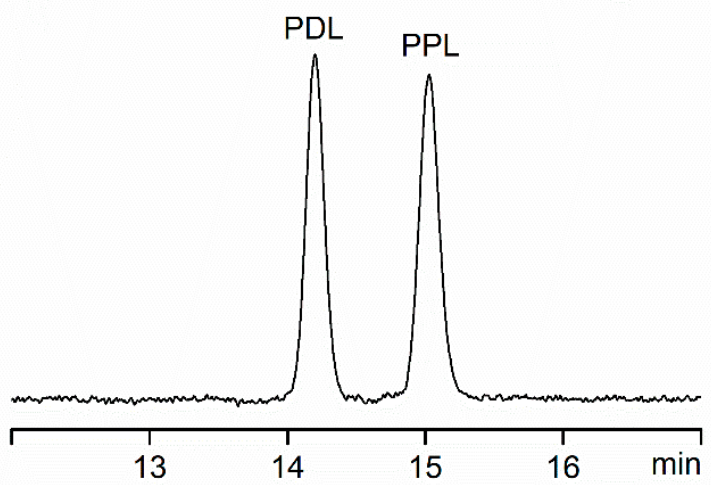

Figure 1. CE separation of PDL and PPL, each prepared at concentration of $5 \mu \mathrm{mol} / \mathrm{L}$ (CSS) and $20 \mu \mathrm{mol} / \mathrm{L}$ (OSS-EOF and OSS-sEOF). (a) OSS-EOF Buffer: $30 \mathrm{mmol} / \mathrm{L} \beta$-alanine, $10 \mathrm{mmol} / \mathrm{L}$ poly(ethylene glycol) dicarboxylic acid, $0.1 \mathrm{mmol} / \mathrm{L}$ DETA; $\mathrm{pH}=3.7$; conditions: $25 \mathrm{kV}$ (approximately $3.7 \mu \mathrm{A}$ ), $21{ }^{\circ} \mathrm{C}$, detection at $210 \mathrm{~nm}$. (b) OSS-sEOF Buffer: as (a) with addition of $0.05 \%$ MHEC; conditions: as (a). (c) CSS Buffer: as (b); conditions: as (a) except $75 \mu \mathrm{A}$ (approximately $2.80 \mathrm{kV}$ ). See Materials and Methods for all other details.

Table 1. Some analytical performance data for the separations of PDL and PPL in the opened (OSS-EOF and OSS-sEOF) and closed (CSS) separation systems.

\begin{tabular}{ccccccc}
\hline Parameter & \multicolumn{2}{c}{ OSS-EOF } & \multicolumn{2}{c}{ OSS-sEOF } & \multicolumn{2}{c}{ CSS } \\
& PDL & PPL & PDL & PPL & PDL & PPL \\
\hline$\mu_{\mathrm{ep}} \times 10^{8}\left(\mathrm{~m}^{2} \mathrm{~V}^{-1} \mathrm{~s}^{-1}\right)$ & 1.74 & 1.66 & 1.83 & 1.75 & 2.52 & 2.37 \\
RSD tm $(\%)$ & 0.3 & 0.3 & 0.4 & 0.4 & 0.5 & 0.5 \\
RSD A $(\%)$ & 2.0 & 1.4 & 3.4 & 2.4 & 2.2 & 1.6 \\
$\mathrm{~N} \times 10^{-3}\left(\mathrm{~m}^{-1}\right)$ & 309 & 310 & 465 & 482 & 162 & 147 \\
LOD $\left(\mu \mathrm{mol}^{-1}\right)$ & 1.20 & 1.10 & 1.50 & 1.40 & 0.06 & 0.07 \\
Resolution & $(1)$ & \multicolumn{2}{c}{1.47} & \multicolumn{2}{c}{3.64} & \multicolumn{2}{c}{3.23}
\end{tabular}

$\mu_{\mathrm{ep}}=$ electrophoretic mobility, $\mathrm{t}_{\mathrm{m}}=$ migration time, $\mathrm{A}=$ peak area for the concentration of the analyte corresponding to $10 \times \mathrm{LOD}, \mathrm{N}=$ the number of theoretical plates, $\mathrm{LOD}=$ concentration limit of detection. See Figure 1 for experimental conditions. ${ }^{(1)}$ Resolution calculated according to [21], this applies to the entire article.

\subsubsection{Repeatability}

As stated in the Introduction, in CE the movement of compounds results from a combination of electroosmotic and electrophoretic velocity. If present, HDF will also affect the ion movement. Consequently, total variability of migration time also consists of contributions from EOF, HDF and 
electrophoretic movement [18]. In line with data in Table 1 we observed that the repeatability of migration times in the three systems under consideration is broadly identical. This observation is further reinforced by the broadly identical repeatability of peak areas as in CE the observed peak areas are affected by the velocity of migration of the separated zones $[22,23]$.

\subsubsection{Efficiency and Resolution}

Although, due to the plug-like profile of EOF, its contribution to zone dispersion should be negligible, from the data in Table 1 we observed an approximately 50\% (PDL) to 55\% (PPL) increase of separation efficiency $(\mathrm{N})$ for the hydrodynamically opened system with suppressed EOF (OSS-sEOF) when compared to a system with EOF present (OSS-EOF). Apart from the addition of the EOF suppressor to the separation buffer in the form of $0.05 \%$ MHEC, all other experimental conditions were kept the same. This increase in efficiency can only in part be ascribed to extra dispersion due to the EOF, and the more likely explanation is that the EOF suppressor reduces adsorption of positively charged components on capillary walls as previously described [14,17]. The increase of separation efficiency is also accompanied by the increase of resolution between PDL to PPL from 1.47 (OSS-EOF) to 3.64 (OSS-sEOF). An approximately $65 \%$ (PDL) to 70\% (PPL) reduction in efficiency when compared to OSS-sEOF was observed when analyzing the model sample using the CSS as shown in Table 1. While the sample and the separation buffer were identical, some other experimental conditions, such as applied current, internal and external diameters as well as the length of the separation capillary and injection plug length, were different in CSS, potentially giving rise to the increase in extra column band broadening. The total difference in plate height between OSS-sEOF and CSS was calculated as

$$
\Delta \mathrm{H}_{\mathrm{diff}, \mathrm{tot}}=\mathrm{H}_{\mathrm{CSS}}-\mathrm{H}_{\mathrm{OSS}-\mathrm{sEOF}}=\frac{\mathrm{L}_{\mathrm{d}, \mathrm{CSS}}}{\mathrm{N}_{\mathrm{CSS}}}-\frac{\mathrm{L}_{\mathrm{d}, \text { OSS-sEOF }}}{\mathrm{N}_{\mathrm{OSS}-\mathrm{sEOF}}}
$$

where the $\mathrm{L}_{\mathrm{d}, \mathrm{CSS}}$ and $\mathrm{L}_{\mathrm{d}, \mathrm{OSS} \text {-sEOF }}$ correspond to the distance from the point of injection to the detector for the CSS and OSS-sEOF, respectively. Then $\Delta \mathrm{H}_{\text {diff,tot }}$ is $4.02 \mu \mathrm{m}$ for PDL and $4.73 \mu \mathrm{m}$ for PPL (See Table 1 for $\mathrm{N}_{\mathrm{CSS}}$ and $\left.\mathrm{N}_{\mathrm{OSS}-\mathrm{sEOF}}\right)$. To assess the injection contribution to the dispersion, the injection plug length had to be estimated for CSS and OSS-sEOF. For CSS, the injected volume $\left(\mathrm{V}_{\text {inj }}\right)$ is fixed at approximately $200 \mathrm{~nL}$, and the sample plug length $\mathrm{L}_{\mathrm{inj}}=3.2 \mathrm{~mm}$ was measured by injecting a solution of dye. OSS employs hydrodynamic injection and the injected volume is calculated according to the Poiseuille-Hagen relationship

$$
\mathrm{V}_{\mathrm{inj}}=\frac{\Delta \mathrm{Ptd}^{4} \pi}{128 \mathrm{~L} \eta}
$$

where $\Delta \mathrm{P}=2000 \mathrm{~Pa}$ is applied injection pressure, $\mathrm{t}=6 \mathrm{~s}$ is injection time, $\mathrm{L}=70 \mathrm{~cm}$ is capillary length and $\eta=8.9 \times 10^{-4}$ Pas is the sample viscosity.

Injection plug length can then be calculated $(\mathrm{d}$ = capillary diameter $)$

$$
\mathrm{L}_{\mathrm{inj}}=\mathrm{V}_{\mathrm{inj}} /\left(\pi \frac{\mathrm{d}^{2}}{4}\right)=1.5 \mathrm{~mm}
$$

The difference in plate height originating from the injection and contributing to the total difference in plate height was calculated as

$$
\Delta \mathrm{H}_{\text {diff, inj }}=\mathrm{H}_{\mathrm{inj}, \text { CSS }}-\mathrm{H}_{\mathrm{inj}, \text { OSS-sEOF }}=\frac{\mathrm{L}_{\text {inj, CSS }}^{2}}{12 \mathrm{~L}_{\mathrm{d}, \text { CSS }}}-\frac{\mathrm{L}_{\text {inj, OSS-sEOF }}^{2}}{12 \mathrm{~L}_{\mathrm{d}, \text { OSS-sEOF }}}=3.56 \mu \mathrm{m}
$$

As the detector slit size was identical $(6 \mathrm{~nm})$ in OSS-sEOF and CSS, the detector contribution to the total dispersion was negligible and it was ignored, as it was several orders of magnitude smaller than the contribution from the injection. The latter accounts for an $89 \%$ (PDL) to $75 \%$ (PPL) increase of the total plate height in CSS. This means that the contribution from diffusion and thermal effects 
only account for the remaining $12-25 \%$ of the total plate height difference. This proportion is perhaps unexpectedly small; however, one must take into account that only a modest increase in power was generated in CSS when compared to OSS-sEOF (0.09 W for OSS-sEOF vs. 0.21 W for CSS).

Despite a significant reduction in efficiency, the resolution between PDL and PPL was only marginally reduced from 3.64 (OSS-sEOF) to 3.23 (CSS).

\subsubsection{Sensitivity}

One of the reasons why the full potential of CE has not been realized, especially in the field of pharmaceutical analysis, is its inferior concentration sensitivity when compared to other separation techniques. This is mainly due to the above-mentioned restrictions on i.d. of capillaries when they are employed as separation compartments. It not only reduces the detector light-path, but it also limits the injection volume. While the concentration sensitivity expressed as LOD $(\mu \mathrm{mol} / \mathrm{L})$ remained broadly identical for OSS-EOF and OSS-sEOF, an approximate 18- to 23-fold improvement in concentration sensitivity was observed for CSS (Table 1). This is mainly due to a 6.4-fold increase of the optical path length. The wider capillary i.d. also permits a larger injection volume ( $257 \mathrm{~nL}$ in CSS vs. $2.9 \mathrm{~nL}$ in OSS) while maintaining the narrow injection sample plug length.

If the typical reporting limit for impurities in API is $0.05 \%(w / w)$ [24] then assuming the nominal main component concentration of $0.1 \mathrm{mg} / \mathrm{mL}$ the required limit of quantitation (LOQ) should be $0.05 \%$ [25], and this corresponds to an LOD approximately at the $0.02 \%$ level. As can be seen in Table 2 , this is achievable for CSS; however, for OSS, the achieved sensitivity is over an order of magnitude worse than required.

Table 2. Required and achieved concentration LOD for OSS-EOF, OSS-sEOF and CSS.

\begin{tabular}{|c|c|c|c|c|c|c|c|c|c|}
\hline \multicolumn{4}{|c|}{ Required LOD } & \multicolumn{6}{|c|}{ Achieved LOD ( $\mu \mathrm{mol} / \mathrm{L})$} \\
\hline \multirow[t]{2}{*}{$\%(w / w)$} & \multirow[t]{2}{*}{$\mathrm{mg} / \mathrm{mL}$} & \multicolumn{2}{|c|}{$\mu \mathrm{mol} / \mathrm{L}$} & \multicolumn{2}{|c|}{ OSS-EOF } & \multicolumn{2}{|c|}{ OSS-sEOF } & \multicolumn{2}{|c|}{ CSS } \\
\hline & & PDL & PPL & PDL & PPL & PDL & PPL & PDL & PPL \\
\hline 0.02 & $2.0 \times 10^{-5}$ & 0.08 & 0.08 & 1.20 & 1.10 & 1.50 & 1.40 & 0.06 & 0.07 \\
\hline
\end{tabular}

This brings the concentration sensitivity of CE in CSS setup close to that of a modern Ultra High-Performance Liquid Chromatography (UHPLC). Similarly, for the absolute injected amount, if for the UHPLC we assume a typical sample concentration of $0.1 \mathrm{mg} / \mathrm{mL}$ and an injection volume of $2 \mu \mathrm{L}$, then for the LOD at $0.02 \%(w / w)$ of the nominal loading of the main component, we inject approximately 40 pg of each component. For CSS, the absolute amount of injected PDL and PPL at LOD level is 4 and $5 \mathrm{pg}$, respectively, which demonstrates the superior mass sensitivity of this technique.

\subsection{Comparison of Hydrodynamically Opened and Closed Separation Systems for Chiral Separations}

CE is often considered a technique of choice for chiral separations [26-29]. This is mainly due to its simplicity, speed of chiral screening and low cost when compared to other separation techniques such as chiral HPLC. In chiral HPLC method development, several chiral columns are usually screened either sequentially [30,31] or in parallel [32-34] in combination with multiple mobile phases. Although ultimately successful, this approach is costly due to the significant cost of chiral stationary phases. It is also time consuming and generates a significant amount of waste. In CE, on the other hand, a small amount of chiral selector is usually added to the separation buffer. Chiral selectors can be at the $\mathrm{pH}$ of the separation buffer, either neutral or charged. If they are neutral, then they either move with EOF or, in the absence of EOF, are stationary. When charged they can move in the same or opposite direction to analytes. The enantioselectivity is achieved by differential interaction of enantiomers with the chiral selector.

To demonstrate the capability of CSS to separate chiral compounds and to study the impact of this hydrodynamical system on chiral separations we first developed the method to separate 
enantiomers of PDL and PPL using the OSS-EOF by adding the negatively charged chiral selector carboxymethyl $\beta$-cyclodextrin (CMBCD) to the separation buffer. Chiral resolution of enantiomers of PDL and PPL was achieved, as shown in Figure 2a, and resolution values are reported in Table 3. In OSS-EOF, the electroosmotic mobility $\left(\mu_{\mathrm{EOF}}\right)$ is in the direction of cathode. This was observed as a negative dip in the baseline in Figure 1a as well as in Figure 2a. The anionic cyclodextrin added to the separation buffer will exhibit under these conditions electrophoretic mobility $\left(\mu_{\mathrm{CD}}\right)$ in the direction of the anode. If $\left|\mu_{\mathrm{EOF}}\right|>\left|\mu_{\mathrm{CD}}\right|$, then the effective mobility of the chiral selector $\left(\mu_{\mathrm{CD}}\right.$,eff $)$ will be low and equal to the difference between $\left|\mu_{\mathrm{EOF}}\right|$ and $\left|\mu_{\mathrm{CD}}\right|$, but it will be in the same cathodic direction as EOF. If on the other hand $\left|\mu_{\mathrm{EOF}}\right|<\left|\mu_{\mathrm{CD}}\right|$ then the effective mobility of the chiral selector will be in the direction of the anode. Regardless of the direction of the effective movement of the anionic chiral selector, its impact on the effective movement of cationic analytes will always be in the opposite direction of their electrophoretic mobilities, and its magnitude will be determined by the strength of the interaction between chiral selector and analytes.

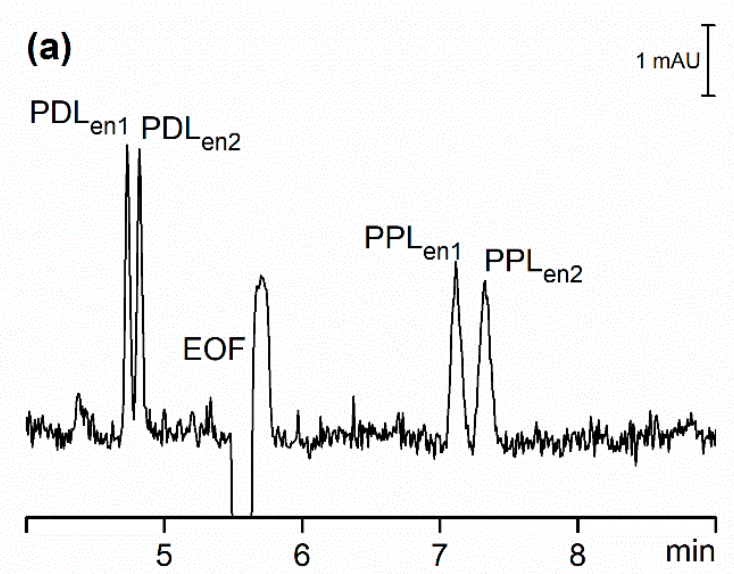

(b)

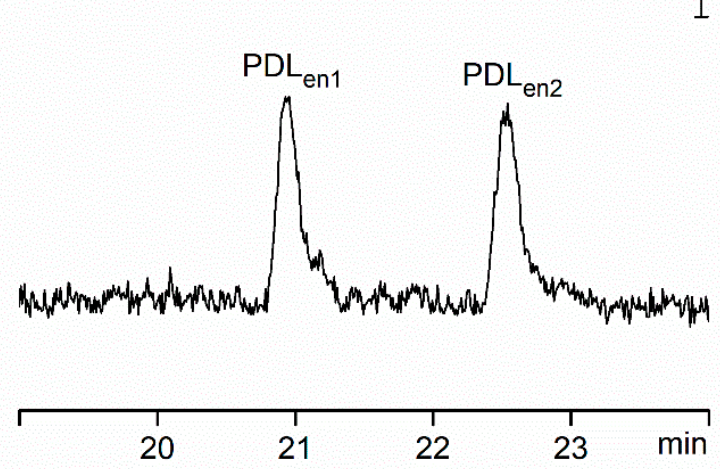

(c)

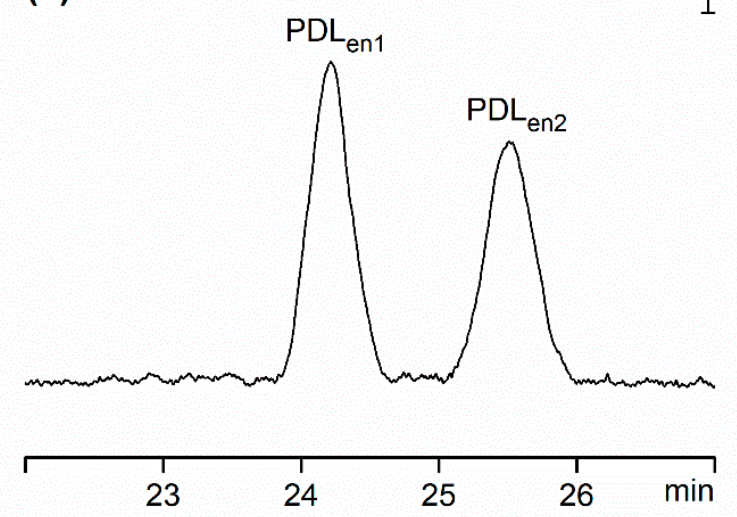

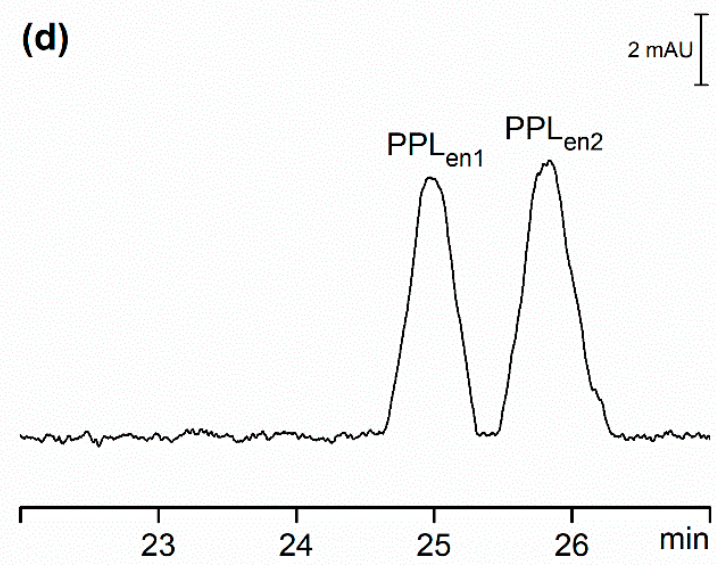

Figure 2. CE separation of PDL and PPL enantiomers, each prepared at concentration of $5 \mu \mathrm{mol} / \mathrm{L}$ (CSS) and $20 \mu \mathrm{mol} / \mathrm{L}$ (OSS-EOF and OSS-sEOF). (a) OSS-EOF Buffer: $30 \mathrm{mmol} / \mathrm{l} \beta$-alanine, $5 \mathrm{mmol} / \mathrm{L}$ poly(ethylene glycol) dicarboxylic acid, $0.1 \mathrm{mmol} / \mathrm{L}$ DETA, $2 \mathrm{mmol} / \mathrm{L} \mathrm{CMBCD;} \mathrm{pH}=3.8$; conditions: $25 \mathrm{kV}$ (approximately $4.5 \mu \mathrm{A}$ ), $21^{\circ} \mathrm{C}$, detection at $210 \mathrm{~nm}$. (b) OSS-sEOF Buffer: as (a) with addition of $0.05 \%$ MHEC; conditions: as (a). (c) CSS Buffer: as (b); conditions: as (a) except $100 \mu \mathrm{A}$ (approximately $3.50 \mathrm{kV}$ ). (d) CSS Buffer: $30 \mathrm{mmol} / \mathrm{L} \beta$-alanine, $1 \mathrm{mmol} / \mathrm{L}$ poly(ethylene glycol) dicarboxylic acid, $0.1 \mathrm{mmol} / \mathrm{L}$ DETA, 0.05\% MHEC, $10 \mathrm{mmol} / \mathrm{L} \mathrm{CEBCD;} \mathrm{pH}=3.9$; conditions: as (c) except $150 \mu \mathrm{A}$ (approximately $3.70 \mathrm{kV}$ ). See Materials and Methods for all other details. 
Table 3. Resolution of PDL and PPL enantiomers in studied systems.

\begin{tabular}{ccccccc}
\hline Chiral Selector & \multicolumn{2}{c}{ OSS-EOF } & \multicolumn{2}{c}{ OSS-sEOF } & \multicolumn{2}{c}{ CSS } \\
& PDL & PPL & PDL & PPL & PDL & PPL \\
\hline CMBCD & $\mathrm{R}_{\mathrm{S}}=1.33$ & $\mathrm{R}_{\mathrm{S}}=1.42$ & $\mathrm{R}_{\mathrm{S}}=5.22$ & r.m. & $\mathrm{R}_{\mathrm{S}}=2.06$ & n.t. \\
CEBCD & n.t. & n.t. & n.t. & n.t. & n.t. & $\mathrm{R}_{\mathrm{s}}=1.36$ \\
\hline \multicolumn{7}{c}{ r.m.-reversed migration, n.t.-not tested, $\mathrm{R}_{\mathrm{s}}$-resolution. See Figure 2.}
\end{tabular}

Table 4 shows the relative movement and mobilities of PDL and PPL enantiomers in OSS-EOF and OSS-sEOF as well as CSS. Electrophoretic movement of positively charged ions of PDL and PPL is in the direction of the cathode and these mobilities, reported in Table 4, were obtained from experiments where the chiral selector was not present (Table 1), ignoring the impact of the ionic strength changes. The resulting effective movement of the enantiomers of PDL and PPL will be determined by the relative magnitude of the EOF, their electrophoretic mobilities and the interaction with the chiral selector. In the case of PDL, the interaction with the chiral selector is relatively weak, and the enantiomers migrate ahead of the EOF marker as it was observed in experiments where the chiral selectors were not used. However, in the case of PPL, this interaction is significantly stronger, and the enantiomers migrate after the EOF marker. The magnitude of the interaction with the chiral selector is presented in Table 4 expressed as the difference between the observed effective mobility in a separation buffer with the addition of the chiral selector and the effective mobility in a system without the chiral selector, while we assume constant electrophoretic mobilities under otherwise identical experimental conditions.

Table 4. Observed and calculated electrophoretic and effective mobility of PDL and PPL enantiomers in studied systems.

\begin{tabular}{cccccccccccc}
\hline System & & \multicolumn{4}{c}{ PDL $_{\text {en1 }}$} & \multicolumn{2}{c}{ PDL $_{\text {en2 }}$} & \multicolumn{2}{c}{ PPL $_{\text {en1 }}$} & \multicolumn{2}{c}{ PPL $_{\text {en2 }}$} \\
& $\mu_{\text {eof }}$ & $\mu_{\text {ep }}$ & $\mu_{\text {eff }}$ & $\mu_{\text {CD }}{ }^{(1)}$ & $\mu_{\text {eff }}$ & $\mu_{\text {CD }}$ & $\mu_{\text {ep }}$ & $\mu_{\text {eff }}$ & $\mu_{\text {CD }}$ & $\mu_{\text {eff }}$ & $\mu_{\text {CD }}$ \\
\hline OSS-EOF & +2.20 & +1.74 & +2.60 & -1.34 & +2.56 & -1.38 & +1.66 & +1.74 & -2.12 & +1.69 & -2.17 \\
OSS-sEOF & 0 & +1.83 & +0.59 & -1.24 & +0.55 & -1.28 & +1.75 & -0.37 & -2.12 & -0.42 & -2.17 \\
CSS & 0 & +2.52 & +1.18 & -1.34 & +1.12 & -1.40 & +2.37 & $+1.08^{(2)}$ & $-1.29^{(2)}$ & $+1.05^{(2)}$ & $-1.32^{(2)}$ \\
\hline
\end{tabular}

(1) chiral selector $\mathrm{CMBCD},{ }^{(2)}$ chiral selector $\mathrm{CEBCD}, \mu_{\mathrm{eof}}, \mu_{\mathrm{ep}}, \mu_{\mathrm{eff}}$-electroosmotic, electrophoretic and effective mobility respectively $\left(\times 10^{-8} \mathrm{~m}^{2} \mathrm{~V}^{-1} \mathrm{~s}^{-1}\right)$, +ve sign represents movement towards cathode, -ve sign represents movement towards anode, $\Delta \mu_{\mathrm{CD}}$-reduction in $\mu_{\text {eff }}$ due to interaction with chiral selector. Values in italic font were calculated using assumptions described in text.

In OSS-sEOF, the observed effective mobilities of PDL enantiomers are in the direction of the cathode; however, they are significantly reduced due to the absence of EOF (Figure 2b). Moreover, the estimated interaction with the chiral descriptor is practically identical as for the OSS-EOF. Peaks for PPL enantiomers were not detected in this separation buffer. Assuming that the interaction of PPL enantiomers with the chiral selector will remain unchanged in OSS-sEOF, the effective mobilities would be in the direction of the anode and not detected on the cathodic end of the capillary as demonstrated in Table 4. Note that the numbers in italic font correspond to the calculated values which were not experimentally verified. In CSS, the electrophoretic mobilities of PDL and PPL are slightly increased probably due to elevated temperature inside the separation compartment as discussed above. However, the calculated interaction with the chiral selector was again identical to the OSS-EOF and OSS-sEOF and both enantiomers were baseline resolved (Table 3). The observed effective mobility of PDL enantiomers was, as in the OSS-sEOF, in the direction of cathode. Replacing the CMBCD chiral selector with electrophoretically less mobile carboxyethyl- $\beta$-cyclodextrin (CEBCD) resulted in a reduced interaction with PPL enantiomers leading to their baseline separation (Figure 2c,d and Table 3) and observed effective mobility in the direction of the cathode (Table 4). 


\subsection{Comparison of Hydrodynamically Opened and Closed Separation Systems for Analysis of Pharmaceuticals in Serum Samples}

Blood serum represents a highly complex sample matrix, as it contains high levels of proteins as well as increased levels of salts, small molecules such as hormones and exogenous components, for example components related to pharmaceutical drugs and their metabolites. Due to this diverse composition, it represents a significant challenge for separation techniques, as it can affect their performance due to protein adsorption to the stationary phase or various components of instrumentation. In CE, adsorption of serum proteins to the capillary walls can cause problems with the reproducibility of EOF and through slow rates of association and dissociation processes between proteins and analytes it can affect peak shape and cause problems with variability of response. In extreme cases, this can result in problems with breakage of the electric current due to protein or analyte precipitation. Additionally, high salt content can cause problems with electrophoretic dispersion.

To demonstrate the suitability of CSS for complex samples we spiked PDL and PPL into a reference serum. We were unable to reliably analyze PDL and PPL spiked to untreated serum using $50 \mu \mathrm{m}$ i.d. capillaries, as their clogging led to frequent breakages of current. In CSS carried out using wide bore capillaries we managed to perform 8-10 consecutive analyses; however, at this point, blockage of the injection device necessitated extensive cleaning. We therefore decided to reduce the amount of serum proteins through precipitation with acetonitrile followed by centrifugation. These deproteinized samples were then used to compare the performance of the three studied systems. In OSS-EOF, the first injection on a new or extensively cleaned capillary usually produced satisfactory results; however, no peaks corresponding to these compounds were observed in consecutive injections, but frequent current breakages were observed. We explained this observation by the irreversible binding of remaining serum proteins on the fused silica capillaries resulting in changes in EOF. The only way to recover these capillaries or achieve reproducible results was to carry out very extensive cleaning of the capillaries lasting up to $40 \mathrm{~min}$ rendering this approach impractical for routine use. This behavior was not observed for OSS-sEOF or CSS, and reproducibility of migration times, observed peak areas, obtained peak efficiencies, sensitivity and resolution for OSS-sEOF and CSS expressed as the average of ten repeated injections of the sample are listed in Table 5. From comparison of data presented in Tables 1 and 5, it can be seen that the electrophoretic mobilities of PDL and PPL were not affected by the matrix. Additionally, results obtained for the repeatability of migration times and observed peak areas were comparable with those obtained for model samples. Marginal reduction in peak efficiency led to a slight reduction in sensitivity; however, the CSS sensitivity is approximately 40 times better than that in OSS-sEOF. Equally, sufficient resolution between PDL and PPL was observed.

Addition of charged cyclodextrin to the separation buffer to some degree reduced the negative impact of serum protein adsorption on capillary walls as, unlike in achiral separations, we were able to observe the separation of PDL enantiomers in OSS-EOF (Figure 3a). Due to the above-mentioned reduction in EOF, PPL enantiomers were not detected on the cathodic end of the capillary. Assuming that the electrophoretic mobilities, as observed in achiral separations, are not affected by the sample matrix, then the PPL enantiomers are due a to strong interaction with CMBCD moving in the direction of anode. The same migration direction was observed for OSS-sEOF and CSS due to the absence of EOF; only PDL enantiomers were resolved and detected when the CMBCD chiral selector was employed (Figure 3b,c). Analogous to chiral separation in model samples, substitution of CMBCD for electrophoretically less mobile CEBCD led to successful separation of PPL enantiomers (Figure 3d). 
Table 5. Some analytical performance data for the separations of PDL and PPL spiked to deproteinized samples of serum in the OSS-sEOF and CSS.

\begin{tabular}{ccccc}
\hline Parameter & \multicolumn{2}{c}{ OSS-sEOF } & \multicolumn{2}{c}{ CSS } \\
& PDL & PPL & PDL & PPL \\
\hline$\mu_{\mathrm{ep}} \times 10^{8}\left(\mathrm{~m}^{2} \mathrm{~V}^{-1} \mathrm{~s}^{-1}\right)$ & 1.75 & 1.66 & 2.50 & 2.36 \\
$\mathrm{RSD} \mathrm{t}(\%)$ & 0.3 & 0.3 & 0.8 & 0.8 \\
$\mathrm{RSD} \mathrm{A}(\%)$ & 2.0 & 1.4 & 1.7 & 3.0 \\
$\mathrm{~N} \times 10^{-3}\left(\mathrm{~m}^{-1}\right)$ & 392 & 410 & 151 & 124 \\
LOD $(\mu \mathrm{mol} / \mathrm{L})$ & 3.4 & 3.2 & 0.08 & 0.08 \\
Resolution & \multicolumn{2}{c}{3.78} & & \multicolumn{2}{c}{2.73} \\
\hline
\end{tabular}

$\mu_{\mathrm{ep}}=$ electrophoretic mobility, $\mathrm{t}_{\mathrm{m}}=$ migration time, $\mathrm{A}=$ peak area for the concentration of the analyte corresponding to $10 \times$ LOD, $\mathrm{N}=$ the number of theoretical plates, LOD $=$ concentration limit of detection. OSS-sEOF Buffer: $30 \mathrm{mmol} / \mathrm{L} \beta$-alanine, $10 \mathrm{mmol} / \mathrm{L}$ poly(ethylene glycol) dicarboxylic acid, $0.1 \mathrm{mmol} / \mathrm{L}$ DETA, $0.05 \% \mathrm{MHEC}$; $\mathrm{pH}=3.7$; conditions: $25 \mathrm{kV}$ (approximately $3.7 \mu \mathrm{A}$ ), $21^{\circ} \mathrm{C}$, detection at $210 \mathrm{~nm}$. CSS Buffer: as OSS-sEOF; conditions: as OSS-sEOF except $75 \mu \mathrm{A}$ (approximately $2.80 \mathrm{kV}$ ). See Materials and Methods for all other details.

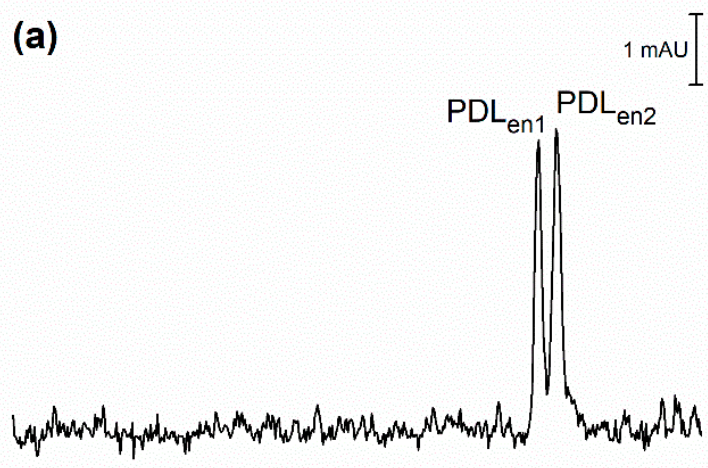

(b)
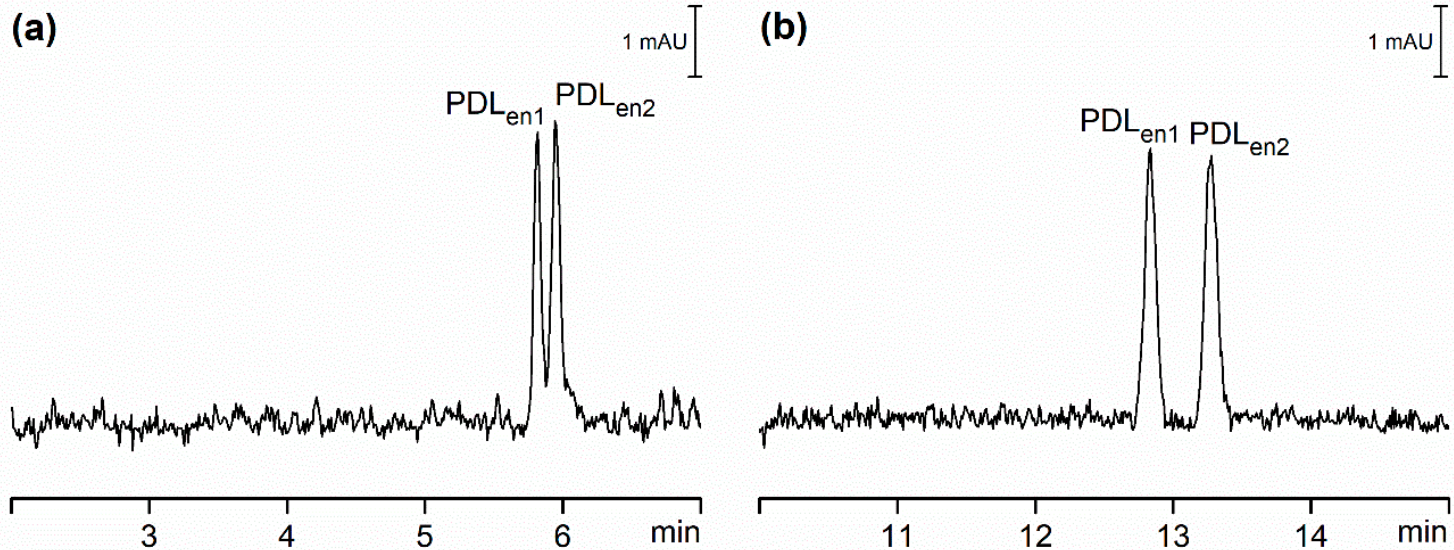

(c)

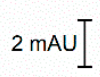

(d)
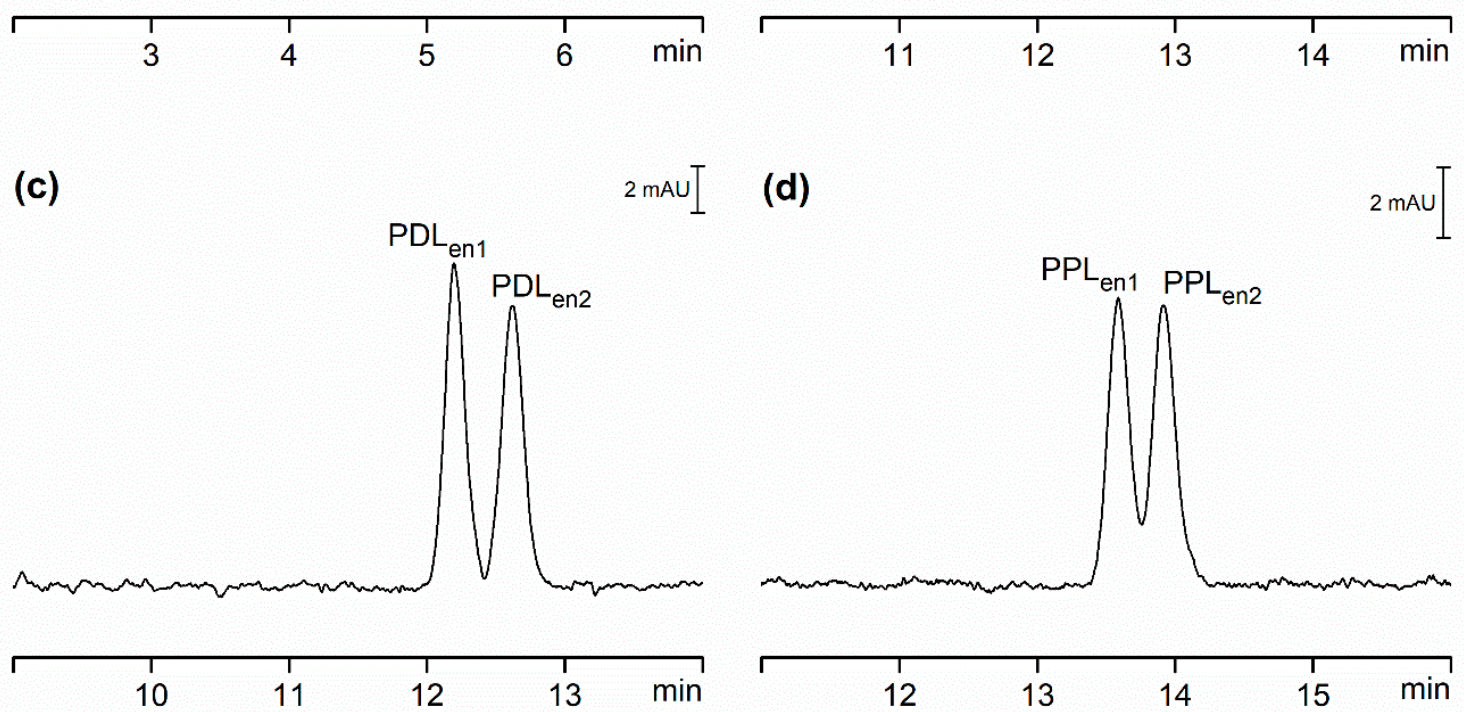

Figure 3. CE separation of PDL and PPL enantiomers, each prepared at concentrations of $5 \mu \mathrm{mol} / \mathrm{L}$ (CSS) and $20 \mu \mathrm{mol} / \mathrm{L}$ (OSS-EOF and OSS-sEOF) spiked into deproteinized serum. (a) OSS-EOF Buffer: $30 \mathrm{mmol} / \mathrm{L} \beta$-alanine, $5 \mathrm{mmol} / \mathrm{L}$ poly(ethylene glycol) dicarboxylic acid, $0.1 \mathrm{mmol} / \mathrm{L} \mathrm{DETA}, 2$ mmol/L CMBCD; $\mathrm{pH}=3.8$; conditions: $25 \mathrm{kV}$ (approximately $4.5 \mu \mathrm{A}$ ). (b) OSS-sEOF Buffer: as (a) with addition of $0.05 \%$ MHEC; conditions: as (a). (c) CSS Buffer: as (b); conditions: as (a) except $150 \mu \mathrm{A}$ (approximately $3.90 \mathrm{kV}$ ). (d) CSS Buffer: $30 \mathrm{mmol} / \mathrm{L} \beta$-alanine, $1 \mathrm{mmol} / \mathrm{L}$ poly(ethylene glycol) dicarboxylic acid, $0.1 \mathrm{mmol} / \mathrm{L}$ DETA, 0.05\% MHEC, $10 \mathrm{mmol} / \mathrm{L} \mathrm{CEBCD;} \mathrm{HH}=3.9$; conditions: as (c) except $150 \mu \mathrm{A}$ (approximately $3.70 \mathrm{kV}$ ). All other conditions as in Figure 2. 
When comparing chiral resolution of PDL and PPL enantiomers in model samples (Table 3) and those where analytes were spiked into the deproteinized serum (Table 6), we observed a significant increase of effective mobilities of analytes in the spiked serum samples (Table 7). This behavior was observed in both OSS-sEOF and CSS systems. Although adequate resolution of enantiomers was achieved, this was again slightly reduced in the spiked serum samples, as shown in Tables 3 and 6 . We hypothesize that this is caused by the formation of ion-pairs between residual cationic blood serum proteins and anionic cyclodextrins $[35,36]$. As a result, there is less cyclodextrin available for enantio-selective separation of PDL and PPL, which minimizes the reduction in $\mu_{\text {eff }}$ due to interaction with the chiral selector $\left(\Delta \mu_{\mathrm{CD}}\right)$ as initially described in Table 4 for model samples that do not contain serum proteins. It is worth noting that the factor by which the effective mobility is increased in spiked serum samples is nearly identical for OSS-sEOF and CSS.

Table 6. Resolution of PDL and PPL enantiomers spiked into deproteinized reference serum in studied systems.

\begin{tabular}{ccccccc}
\hline Chiral Selector & \multicolumn{2}{c}{ OSS-EOF } & \multicolumn{2}{c}{ OSS-sEOF } & \multicolumn{2}{c}{ CSS } \\
& PDL & PPL & PDL & PPL & PDL & PPL \\
\hline CMBCD & $\mathrm{R}_{\mathrm{S}}=1.16$ & r.m. & $\mathrm{R}_{\mathrm{s}}=2.68$ & n.t. & $\mathrm{R}_{\mathrm{s}}=1.46$ & n.t. \\
CEBCD & n.t. & n.t. & n.t. & n.t. & n.t. & $\mathrm{R}_{\mathrm{s}}=1.04$ \\
\hline \multicolumn{4}{c}{ r.m.-reversed migration, n.t.-not tested, $\mathrm{R}_{\mathrm{s}}$-resolution. }
\end{tabular}

Table 7. Comparison of effective mobilities of enantiomers of PDL and PPL in model samples and in spiked serum samples.

\begin{tabular}{|c|c|c|c|c|c|}
\hline \multirow[t]{2}{*}{$\begin{array}{l}\text { Chiral } \\
\text { Selector }\end{array}$} & \multirow[t]{2}{*}{ Analyte } & \multicolumn{2}{|c|}{$\begin{array}{c}\text { OSS-sEOF } \\
\mu_{\text {eff }} \times 10^{8}\left(\mathrm{~m}^{2} \mathrm{~V}^{-1} \mathrm{~s}^{-1}\right)\end{array}$} & \multicolumn{2}{|c|}{$\begin{array}{c}\text { CSS } \\
\mu_{\mathrm{eff}} \times 10^{8}\left(\mathrm{~m}^{2} \mathrm{~V}^{-1} \mathrm{~s}^{-1}\right)\end{array}$} \\
\hline & & Model Sample & Spiked Serum & Model Sample & Spiked Serum \\
\hline \multirow{2}{*}{ CMBCD } & $\mathrm{PDL}_{\mathrm{en} 1}$ & 0.59 & 0.96 & 1.18 & 2.10 \\
\hline & $\mathrm{PDL}_{\mathrm{en} 2}$ & 0.55 & 0.93 & 1.12 & 2.03 \\
\hline \multirow{2}{*}{ CEBCD } & $\mathrm{PPL}_{\mathrm{en} 1}$ & r.m. & n.t. & 1.08 & 1.99 \\
\hline & $\mathrm{PPL}_{\mathrm{en} 2}$ & r.m. & n.t. & 1.05 & 1.94 \\
\hline
\end{tabular}

r.m.- reversed migration, n.t.-not tested.

\section{Materials and Methods}

\subsection{Instrumentation and Software}

The CE experiments with hydrodynamically closed separation compartment were performed using an EA Electrophoretic Analyzer (Villa-Labeco, Spišská Nová Ves, Slovakia), assembled in the single-column configuration of the separation unit equipped with a Spectra 100 photometric detector (Thermo Separation Products, San Jose, CA, USA) operating at $210 \mathrm{~nm}$. Capillaries made of fluorinated ethylene-propylene copolymer (Villa-Labeco) were $30 \mathrm{~cm}(20 \mathrm{~cm}$ to detector) $\times 320 \mu \mathrm{m}$ i.d. and $700 \mu \mathrm{m}$ outer diameter (o.d). Samples were introduced using an injection valve equipped with a $200 \mathrm{~nL}$ internal sample loop (Villa-Labeco). Instrument operated at room temperature $\left(21^{\circ} \mathrm{C}\right)$. All data were collected and analysed using ACES (v. 1.59) software (Villa-Labeco).

The CE experiments with hydrodynamically opened separation compartment were performed using a PrinCE unit (Prince Technologies, Emmen, The Netherlands), equipped with a Lambda 1000 UV/VIS photometric detector (Bischoff Analysentechnik, Leonberg, Germany) operating at $210 \mathrm{~nm}$. Fused silica capillaries (Composite Metal Services, Hallow, USA) were $70 \mathrm{~cm}(26.5 \mathrm{~cm}$ to detector) $\times$ $50 \mu \mathrm{m}$ i.d. and $375 \mu \mathrm{m}$ o.d. Samples were introduced hydrodynamically to the capillary by applying 20 mbar for $6 \mathrm{~s}$. The temperature of the capillary and the samples was maintained at $21^{\circ} \mathrm{C}$. All data were collected and analyzed using Axxiom 737 v. 3.91 (Axxiom Chromatography, Moorpark, CA, USA) software.

ACD/Labs Percepta (v. 2018) was used to calculate pKa values of model analytes (ACD/pKa GALAS). 


\subsection{Chemicals and Reagents}

Pharmaceutical standards of PDL and PPL (in the form of propranolol hydrochloride) were obtained from Sigma-Aldrich (Steinheim, Germany), and CMBCD and CEBCD (both in the form of sodium salt) were obtained from Cyclolab (Budapest, Hungary). Methylhydroxyethylcellulose 30,000 (MHEC; Serva, Heidelberg, Germany) was purified on a mixed-bed ion exchanger prior to addition to separation buffers at $0.05 \%(w / v)$ concentrations. All aqueous solutions were prepared with water demineralized by a Pro-PS purification system (Labconco, Kansas City, KS, USA). Samples containing serum were acidified by a $3 \mathrm{mmol} / \mathrm{L}$ aqueous solution of acetic acid. Acidified serum samples were either injected directly into the $\mathrm{CE}$ equipment or the proteins were removed by precipitation with acetonitrile before the injection. All other chemicals were of analytical grade purity.

\section{Conclusions}

Capillary electrophoresis in hydrodynamically closed separation systems facilitate the use of wide bore capillaries. Although some loss of efficiency for model samples of pharmaceutically relevant compounds was observed, this loss was proven to originate mainly from injection dispersion and only to a small part from thermal effects. While the resolution of these compounds was maintained, this loss was significantly offset by an approximately 18-23-fold increase in concentration sensitivity. The significance of this increase is particularly relevant for pharmaceutical analysis as it brings capillary electrophoresis to the required sensitivity level comparable with modern liquid chromatography. Moreover, it was demonstrated that capillary electrophoresis in hydrodynamically closed systems can be successfully applied to the chiral separation of pharmaceutical drugs in complex biological matrices such as blood serum.

Author Contributions: Conceptualization, R.S. and M.M.; methodology, R.S., J.H. and M.G.S; software, J.H.; validation, R.S., J.H. and M.M; formal analysis, R.S. and J.H.; investigation, R.S. and M.G.S.; resources, M.M.; data curation, R.S. and J.H.; writing — original draft preparation, R.S. and M.M.; writing-review and editing, R.S. and J.H.; visualization, J.H. and R.S.; supervision, M.G.S.; project administration, R.S. and M.M.; funding acquisition, M.M. and R.S. All authors have read and agreed to the published version of the manuscript.

Funding: This research was funded by the Slovak Research and Development Agency (APVV-17-0318 and APVV-0259-12), and the Slovak Grant Agency for Science (VEGA 1/0787/18). This work is partially outcome of the project ITMS 26240220034 of the Agency of the Ministry of Education, Science, Research and Sport of the Slovak Republic for the Structural Funds of EU, and the project CIII-RO-0010-15-2021 of Central European Exchange Program for University Studies.

Acknowledgments: The authors thank Dalibor Ješko for technical support. Roman Szucs acknowledges Pfizer R\&D UK Limited for support provided during authoring this manuscript.

Conflicts of Interest: The authors declare no conflict of interest.

\section{Abbreviations}

$\begin{array}{ll}\text { CE } & \text { Capillary electrophoresis } \\ \text { EOF } & \text { Electroosmotic flow } \\ \text { HPLC } & \text { High-performance liquid chromatography } \\ \text { i.d. } & \text { Internal diameter } \\ \text { LOD } & \text { Limit of detection } \\ \text { CSS } & \text { Hydrodynamically closed separation system with suppressed electroosmotic flow } \\ \text { OSS } & \text { Hydrodynamically opened separation system } \\ \mu_{\mathrm{ep}} & \text { Electrophoretic mobility } \\ \text { HDF } & \text { Hydrodynamic flow } \\ \text { PPL } & \text { Propranolol } \\ \text { PDL } & \text { Pindolol } \\ \text { OSS-EOF } & \text { Hydrodynamically opened separation system with electroosmotic flow } \\ \text { OSS-sEOF } & \text { Hydrodynamically opened separation system with suppressed electroosmotic flow } \\ \text { MHEC } & \text { Methylhydroxyethylcelullose }\end{array}$




$\begin{array}{ll}\text { DETA } & \text { Diethylenetriamine } \\ \mathrm{V}_{\text {inj }} & \text { Injected volume } \\ \mathrm{d} & \text { Capillary diameter } \\ \mathrm{API} & \text { Active pharmaceutical ingredient } \\ \text { LOQ } & \text { Limit of quantitation } \\ \mathrm{UHPLC} & \text { Ultra high-performance liquid chromatography } \\ \mathrm{CMBCD} & \text { Carboxymethyl- } \beta \text {-cyclodextrin } \\ \mu_{\mathrm{EOF}} & \text { Electroosmotic mobility } \\ \mu_{\mathrm{CD}} & \text { Electrophoretic mobility of chiral selector } \\ \mu_{\mathrm{CD}, \mathrm{eff}} & \text { Effective mobility of chiral selector } \\ \mathrm{CEBCD} & \text { Carboxyethyl- } \beta \text {-cyclodextrin } \\ \Delta \mu_{\mathrm{CD}} & \text { Reduction of electrophoretic mobility due to chiral selector } \\ \text { o.d. } & \text { Outer diameter }\end{array}$

\section{References}

1. Yıldırım, S.; Erkmen, C.; Uslu, B. Novel Trends in Analytical Methods for $\beta$-Blockers: An Overview of Applications in the Last Decade. Crit. Rev. Anal. Chem. 2020, 1-39. [CrossRef] [PubMed]

2. El Deeb, S.; Wätzig, H.; El-Hady, D.A.; Van De Griend, C.E.S.; Scriba, G.K.E. Recent advances in capillary electrophoretic migration techniques for pharmaceutical analysis (2013-2015). Electrophoresis 2016, 37, 1591-1608. [CrossRef] [PubMed]

3. Phillips, T.M. Recent advances in CE and microchip-CE in clinical applications: 2014 to mid-2017. Electrophoresis 2018, 39, 126-135. [CrossRef] [PubMed]

4. Huhn, C.; Ramautar, R.; Wuhrer, M.; Somsen, G.W. Relevance and use of capillary coatings in capillary electrophoresis-mass spectrometry. Anal. Bioanal. Chem. 2010, 396, 297-314. [CrossRef]

5. Gaš, B.; Kenndler, E. Dispersive phenomena in electromigration separation methods. Electrophoresis 2000, 21, 3888-3897. [CrossRef]

6. Gaš, B.; Štědrý, M.; Kenndler, E. Peak broadening in capillary zone electrophoresis. Electrophoresis 1997, 18, 2123-2133. [CrossRef]

7. Junaid, T.; Wu, X.; Thanukrishnan, H.; Venkataramanan, R. Therapeutic Drug Monitoring. In Clinical Pharmacy Education, Practice and Research; Thomas, D., Ed.; Elsevier: Amsterdam, The Netherlands, 2019; pp. 425-436.

8. Virtanen, R. Zone electrophoresis in narrow-bore tube employing potentiometric detection. A theoretical and experimental study. Acta Polytech. Scand. Chem. Technol. Ser. 1974, 123, 1-67.

9. Yin, H.; Keely-Templin, C.; McManigill, D. Preparative capillary electrophoresis with wide-bore capillaries. J. Chromatogr. A 1996, 744, 45-54. [CrossRef]

10. Valkó, I.E.; Porras, S.P.; Riekkola, M.-L. Capillary electrophoresis with wide-bore capillaries and non-aqueous media. J. Chromatogr. A 1998, 813, 179-186. [CrossRef]

11. Kaniansky, D.; Masár, M.; Bielčíková, J. Electroosmotic flow suppressing additives for capillary zone electrophoresis in a hydrodynamically closed separation system. J. Chromatogr. A 1997, 792, 483-494. [CrossRef]

12. Mikkers, F.; Everaerts, F.; Verheggen, T. Concentration distributions in free zone electrophoresis. J. Chromatogr. A 1979, 169, 1-10. [CrossRef]

13. Ramos-Payán, M.; Ocaña-Gonzalez, J.A.; Fernández-Torres, R.M.; Llobera, A.; Bello-López, M.Á. Recent trends in capillary electrophoresis for complex samples analysis: A review. Electrophoresis 2018, 39, 111-125. [CrossRef] [PubMed]

14. Hajba, L.; Guttman, A. Recent advances in column coatings for capillary electrophoresis of proteins. $\operatorname{Tr} A C$ Trends Anal. Chem. 2017, 90, 38-44. [CrossRef]

15. Štěpánová, S.; Kašička, V. Recent applications of capillary electromigration methods to separation and analysis of proteins. Anal. Chim. Acta 2016, 933, 23-42. [CrossRef]

16. Reijenga, J.; Kenndler, E. Computational simulation of migration and dispersion in free capillary zone electrophoresis. J. Chromatogr. A 1994, 659, 403-415. [CrossRef]

17. Wang, A.-J.; Feng, J.-J.; Dong, W.-J.; Lu, Y.-H.; Li, Z.-H.; Riekkola, M.-L. Spermine-graft-dextran non-covalent copolymer as coating material in separation of basic proteins and neurotransmitters by capillary electrophoresis. J. Chromatogr. A 2010, 1217, 5130-5136. [CrossRef] 
18. Kaniansky, D.; Marak, J.; Masár, M.; Iványi, F.; Madajová, V.; Šimuničová, E.; Zelenská, V. Capillary zone electrophoresis in a hydrodynamically closed separation system with enhanced sample loadability. J. Chromatogr. A 1997, 772, 103-114. [CrossRef]

19. Foret, F.; Křivánková, L.; Boček, P. Capillary Zone Electrophoresis; VCH: Weinheim, Germany, 1993.

20. Lucy, C.A.; Macdonald, A.M.; Gulcev, M.D. Non-covalent capillary coatings for protein separations in capillary electrophoresis. J. Chromatogr. A 2008, 1184, 81-105. [CrossRef]

21. The United States Pharmacopeial Convention. Capillary Electrophoresis. Available online: https://www.usp.org/sites/default/files/usp/document/harmonization/biotechnology/harmonizationseptember-2019-m859.pdf (accessed on 2 August 2020).

22. Vindevogel, J.; Szücs, R.; Sandra, P. Reproducibility of migration times and propagation of error in micellar electrokinetic chromatography. J. Microcolumn Sep. 1992, 4, 399-404. [CrossRef]

23. Altria, K.D. Essential peak area normalisation for quantitative impurity content determination by capillary electrophoresis. Chromatographia 1993, 35, 177-182. [CrossRef]

24. International Conference on Harmonisation of Technical Requirements of Technical Requirements for Registration of Pharmaceuticals for Human Use. ICH Harmonised Tripartite Guideline: Impurities in New Drug Substances Q3A(R2). Available online: https://database.ich.org/sites/default/files/Q3A\%28R2\%29\% 20Guideline.pdf (accessed on 31 July 2020).

25. International Conference on Harmonisation of Technical Requirements of Technical Requirements for Registration of Pharmaceuticals for Human Use. ICH Harmonised Tripartite Guideline: Validation of Analytical Procedures: Text and Methodology Q2(R1). Available online: https:/database.ich.org/sites/ default/files/Q2\%28R1\%29\%20Guideline.pdf (accessed on 31 July 2020).

26. Bernardo-Bermejo, S.; Sánchez-López, E.; Castro-Puyana, M.; Marina, M.L. Chiral capillary electrophoresis. TrAC Trends Anal. Chem. 2020, 124, 115807. [CrossRef]

27. Fanali, S.; Chankvetadze, B. Some thoughts about enantioseparations in capillary electrophoresis. Electrophoresis 2019, 40, 2420-2437. [CrossRef] [PubMed]

28. Yu, R.F.; Quirino, J.P. Chiral Selectors in Capillary Electrophoresis: Trends during 2017-2018. Molecules 2019, 24, 1135. [CrossRef] [PubMed]

29. Schmid, M.G.; Hägele, J.S. Separation of enantiomers and positional isomers of novel psychoactive substances in solid samples by chromatographic and electrophoretic techniques-A selective review. J. Chromatogr. A 2020, 1624, 461256. [CrossRef] [PubMed]

30. Andersson, M.E.; Aslan, D.; Clarke, A.; Roeraade, J.; Hagman, G. Evaluation of generic chiral liquid chromatography screens for pharmaceutical analysis. J. Chromatogr. A 2003, 1005, 83-101. [CrossRef]

31. Perera, R.W.H.; Abraham, I.; Gupta, S.; Kowalska, P.; Lightsey, D.; Marathaki, C.; Singh, N.S.; Lough, W.J. Screening approach, optimisation and scale-up for chiral liquid chromatography of cathinones. J. Chromatogr. A 2012, 1269, 189-197. [CrossRef]

32. Sajonz, P.; Gong, X.; Leonard, W.R.; Biba, M.; Welch, C.J. Multiparallel chiral method development screening using an 8-channel microfluidic HPLC system. Chirality 2006, 18, 803-813. [CrossRef]

33. Welch, C.J.; Sajonz, P.; Biba, M.; Gouker, J.; Fairchild, J. Comparison of Multiparallel Microfluidic HPLC Instruments for High Throughput Analyses in Support of Pharmaceutical Process Research. J. Liq. Chromatogr. Relat. Technol. 2006, 29, 2185-2200. [CrossRef]

34. God, R.; Gumm, H. Parallel HPLC in High-Throughput Analysis and Purification. In Analysis and Purification Methods in Combinatorial Chemistry; Yan, B., Ed.; John Wiley \& Sons, Inc.: New York, NY, USA, 2004; Volume 163, pp. 307-320.

35. Rathore, A.S.; Horváth, C. Cyclodextrin aided separation of peptides and proteins by capillary zone electrophoresis. J. Chromatogr. A 1998, 796, 367-373. [CrossRef]

36. Serno, T.; Geidobler, R.; Winter, G. Protein stabilization by cyclodextrins in the liquid and dried state. Adv. Drug Deliv. Rev. 2011, 63, 1086-1106. [CrossRef]

(C) 2020 by the authors. Licensee MDPI, Basel, Switzerland. This article is an open access article distributed under the terms and conditions of the Creative Commons Attribution (CC BY) license (http://creativecommons.org/licenses/by/4.0/). 